\title{
Radiation Shielding for Fusion Reactors
}

\author{
R. T. Santoro \\ Oak Ridge National Laboratory \\ Oak Ridge, TN 37831-6363 USA
}

\begin{abstract}
Radiation shiclding requircments for fusion reactors present different problems than those for fission reactors and accelerators. Fusion devices, particularly tokamak reactors, are complicated by geometry constraints that complicate disposition of fully effective shielding. This paper reviews some of these shielding issues and suggested solutions for optimizing the machine and biological shielding. Radiation transport calculations are essential for predicting and confirming the nuclear performance of the reactor and, as such, must be an essential part of the reactor design process. Development and optimization of reactor components from the first wall and primary shielding to the penetrations and containment shielding must be carried out in a sensible progression. Initial results from one-dimensional transport calculations are used for scoping studies and are followed by detailed two- and three-dimensional analyses to effectively characterize the overall radiation environment. These detail model calculations are essential for accounting for the radiation leakage through ports and other penetrations in the bulk shield. Careful analysis of component activation and radiation damage is cardinal for defining remote handling requirements, in-situ replacement of components, and personnel access at specific locations inside the reactor containment vessel.
\end{abstract}

KEYWORDS: fusion reactor, shielding, nuclear heating, radiation damage, dose, radiation transport, cross sections

\section{Introduction}

Shielding for fusion reactors depends on the operating parameters and physics and engineering requirements specified for the machine. Total shield thickness is determined from radiation constraints for invessel components, particularly the superconducting toroidal (TF) and poloidal (PF) field coils. Shield composition is governed by blanket performance requirements, critical component replacement and remote maintenance criteria, and, in some cases, handson operations to expedite replacement of critical components or routine maintenance.

Designing shielding for a fusion reactor is complicated by the geometry of the device, large neutral beam injection, heating, maintenance and diagnostic ports, gaps and slits, and dissimilar dose standards for personnel and equipment protection. Shielding must (1) protect the TF and PF coils that are essential to reactor operation (in-vessel shielding) and (2) safeguard operating personnel and the public (ex-vessel shielding). For fission reactors and accelerators, radiation can be reduced by the disposition shielding around the reactor core or accelerator target. Penetrations in these shields are generally tailored for specific experimental use.

A summary of fusion reactor shielding issues is presented. Much of the information presented here is based on shielding analyses and nuclear design calculations carried out for the International Thermonuclear Experimental Reactor (ITER) ${ }^{1}$.

\section{Shielding vs. Reactor Geometry}

Plasma physicist and systems designers specify operating parameters for the reactor. These include the first wall neutron loading and fluence, fusion power, and component parameters that must be controlled to achieve performance objectives. The most critical shielding requirement is protection of the superconducting coils (SCC) from excessive nuclear heating, radiation damage, dose, and neutron fluence. Radiation exposure of remote maintenance equipment and diagnostic instrumentation must also be within prescribed limits. Any requirement for hands-on maintenance inside the cryostat will entail further reduction of the plasma neutron flux..

A cross-sectional view of a tokamak reactor is shown in Fig. 1. The blanket-shield assembly, having nominal thickness $T_{B S}$, surrounds the plasma and converts the fusion energy to heat. The blanket, whether designed as a shielding or tritium-breeding assembly, is designed to convert $\sim 99 \%$ of the neutron energy to heat. A shield that surrounds the blanket provides additional radiation protection to the TF coils. $T_{B S}$ is determined mainly on the basis of radiation damage and nuclear heating rate limits specified for the TF coils. Radiation attenuation must be sufficient to minimize the fast neutron fluence and displacement damage to the coil and stabilizer as well as minimizing the total dose to the coil winding insulation. For example, the resistance of the stabilizer increases with displacements per atom (dpa) in the conductor that is balanced by increasing the stabilizer cross-section area resulting in a larger $T_{M}$ and greater coil cost.

In tokamak reactors, the SSC's operate at cryogenic temperature $\left(4^{\circ} \mathrm{K}\right)$. Each watt of thermal power deposited in the magnets by neutrons and secondary gamma rays requires $\sim 500$ watts of refrigeration power to remove the added heat. The blanket-shield attenuation requircd to reducc the nuclear heating rate in the TF coils can be estimated from $\left(\mathrm{P}_{n} / \mathrm{P}_{\mathrm{scc}}\right)$ where $\mathrm{P}_{\mathrm{n}}$ is the total 
fusion power and $\mathrm{P}_{\mathrm{scc}}$ is the nuclear heating rate limit in the SCC (TF plus PF). Heating rate limits in superconducting TF coils are typically $10-20 \mathrm{~kW}$. For reactors designed to produce 1-10 $\mathrm{GW}$ of fusion power, the blanket-shield attenuation factor to assure heating rate limits are not exceeded in the coils is $10^{5}$ to $10^{6}$. In general, an inboard shield thickness, $T_{B S}$, of $\geq 1 \mathrm{~m}$ is required to achieve this reduction.

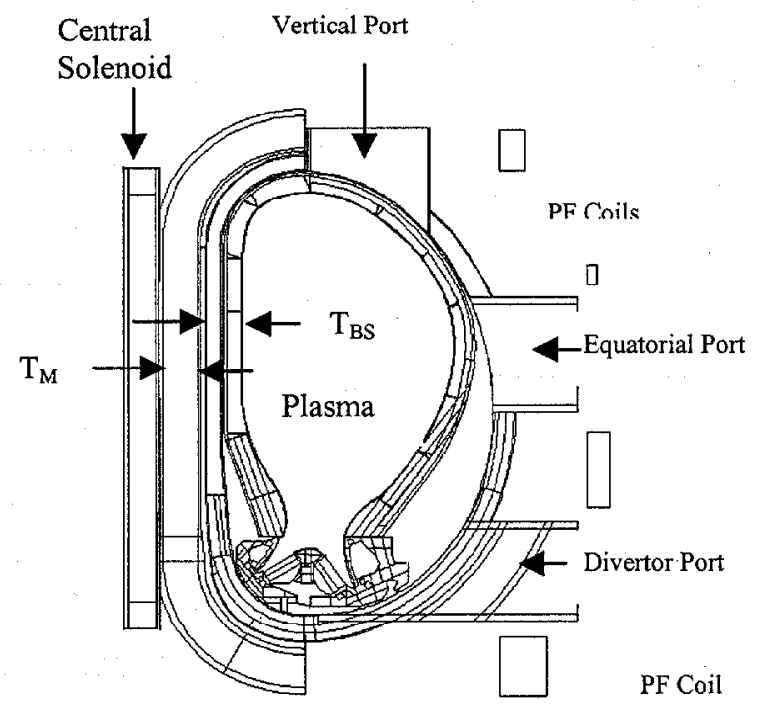

Fig. 1. Cross-Section of a Tokamak Reactor

One of the design requirements for ITER was that dose rates inside the cryostat be low enough to permit human access for rescue and maintenance activities. The dose rate for limited human access inside the cryostat at one-month after reactor shutdown was specified to be $\sim 100 \mu \mathrm{Sv} / \mathrm{h}$. This corresponds to $\sim 7-8$ orders of magnitude smaller dose rate than that at the first wall region. In ITER the nuclear heating rate limit in the toroidal field coils was stipulated to be $17 \mathrm{~kW}$, which is nominally five orders of magnitude smaller than the ITER fusion power $(1.5 \mathrm{GW})$. Allowing for decay after shutdown, the constraint to reduce the dose-rate to $\sim 100$ $\mu \mathrm{Sv} / \mathrm{h}$ requires a shield that provides an additional $\sim 2-3$ orders of magnitude radiation attenuation than required to satisfy the nuclear heating limit.

As seen in Fig. 1, the inboard shield dimensions are constrained by the available space between the plasma and the inboard TF coil leg dictating careful design of the blanket-shield thickness and composition. Although there is more space available for shielding on the outboard side of the plasma, the presence of the large ports reduce shielding effectiveness and particular care must be paid to shielding each major penetration particularly the neutral beam injection ports.

\section{Methods of Shield Analysis}

Table 1 lists some of the radiation transport and activation codes and nuclear data currently being used to support fusion reactor shield design.

Table 1. Radiation Transport Codes and Data

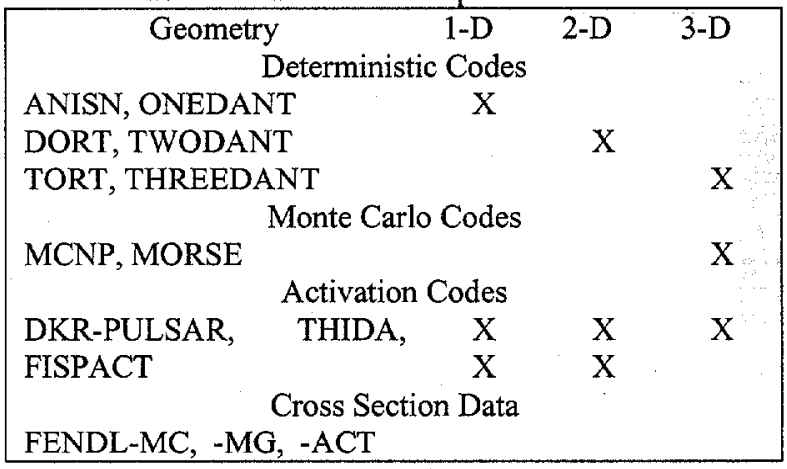

For initial nuclear analyses, one-dimensional (1-D) calculations are used primarily for shield configuration and material optimization. These data offer reactor designers initial guidance on

- basic reactor neutronic parameters,

- component dimensions,

- material compositions,

- shielding efficiency,

- energy release distributions,

- sources of residual radioactivity and

- sensitivity analysis.

Two- and three-dimensional radiation transport codes are required to take into account the toroidal geometry and the presence of large ports and other penetrations in the shield assembly. Two-dimensional methods are used to analyze components of the reactor that can be characterized by symmetry about a single axis. Three dimensional transport methods are used for detailed analysis of ports and penetrations and for assessing the effects of radiation on components outside the primary shielding, i.e., electrical connections, coolant pipes, diagnostic systems, etc.

\section{One-Dimensional Modeling and Scoping Analyses}

Scoping calculations for providing preliminary neutronics information are most readily performed using one-dimensional transport methods. Fig. 2 shows a toroidal cylindrical reactor model that simultaneously includes the inboard and outboard components of the reactor. The dimensions of the components are taken 
from the engineering drawings furnished by designers. Plasma physicists define the plasma radius and the distance from the main axis to the plasma center (major radius). The $14.1 \mathrm{MeV}$ neutrons produced in DT reactions in the plasma migrate through the components dcpositing energy and producing secondary gamma rays. Calculated nuclear responses are generally normalized to the first wall neutron loading ( $M W \mathrm{~m}^{-2}$ ) or the total fusion power (MW). One-dimensional codes are used to calculate the radial dependence of the neutron and gamma-ray flux in the machine components.

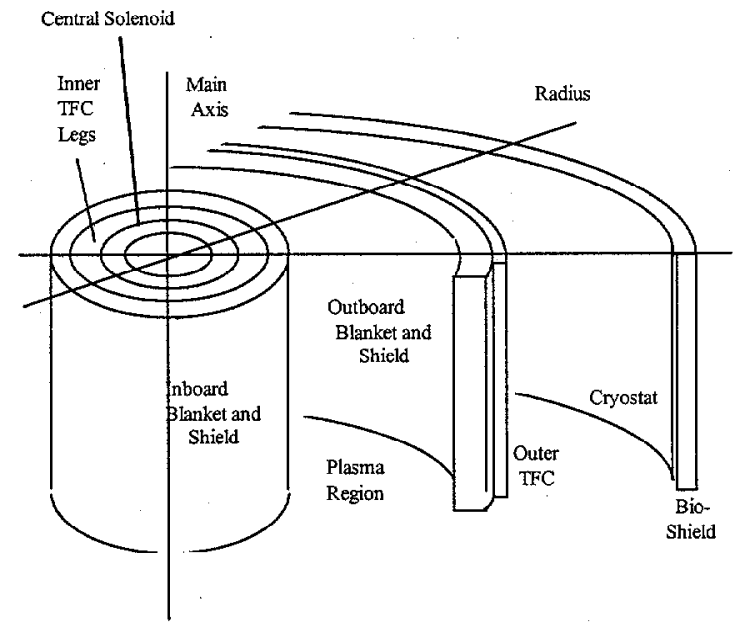

Fig. 2. Toroidal One-Dimensional Model of a Fusion Reactor

Fig. 3. shows the radial dependence of the neutron and gamma ray flux in the inboard components of the reactor. The component dimensions correspond to those in ITER. The flux distributions are plotted as a function of distance from the reactor axis. Included in the figure are the total neutron and gamma-ray fluxes, the neutron flux $>0.1 \mathrm{MeV}$, and the thermal neutron and $14.1 \mathrm{MeV}$ neutron distributions.

Specific radiation responses, $\mathrm{R}_{\mathrm{n}, \mathrm{r}}(\mathrm{r})$, are ascertained by folding the neutron and/or gamma-ray flux, $\Phi_{n, \gamma}(\mathrm{E}, \mathrm{r})$, with desired response function, $\Gamma_{\mathrm{n}, \gamma}(\mathrm{E})$, to estimate parameters of interest using

$$
\mathbf{R}_{\mathrm{n}, \gamma}(\mathrm{r})=\int \Phi_{\mathrm{n}, \gamma}(\mathrm{E}, \mathrm{r}) \Gamma_{\mathrm{n}, \gamma}(\mathrm{E}) \mathrm{dE}
$$

The use of 1-D methods for sensitivity calculations is demonstrated in Fig. 4. Plotted in the figure is the total nuclear heating in the TF coils as a function of the composition of the blanket shield assembly. For this calculation, it is assumed that the assembly is comprised of stainless steel and water. Calculations are carried out for different steel-water mixtures in the blanket and shield. Heating in the coil is minimized when the material composition is $\sim 75 \% \mathrm{SS}-25 \%$ water. Also shown in the figure is the advantage gained when the boron concentration in the SS is increased. Increasing the concentration of boron in steel, particularly in the structural components at rear of the shield, reduces the thermal neutron flux leaking form the shield and, as a result, fewer neutron capture gamma rays $(\sim 8 \mathrm{MeV})$ are produced in the coil structure.

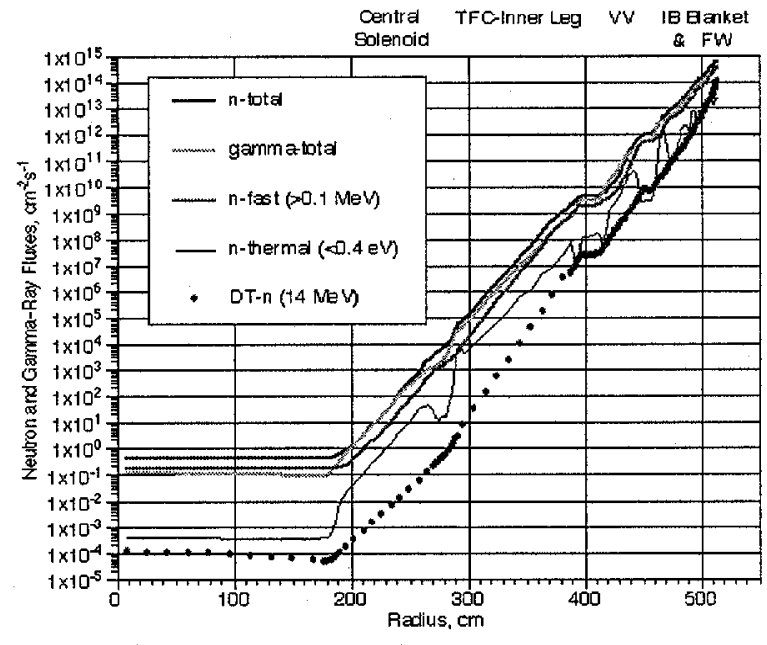

Fig. 3. Radial Dependence of the Neutron and Gamma Ray Flux in the Inboard Side of the Reactor in Fig. 1

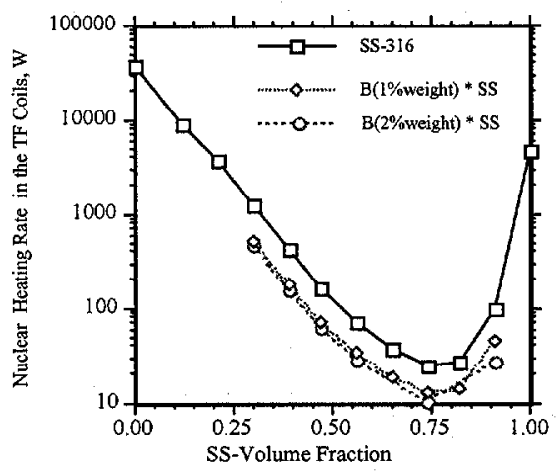

Fig. 4 Nuclear Heating Rate in the TF Coils vs. Steel Fraction in the Blanket-Shield Assembly

One of the difficulties encountered in 1-D analyses is accurate homogenization of blanket and shield components. Homogenization of the blanket is difficult because the disposition and composition of materials varies toroidally and it is not possible to accurately account for joining assemblies, electrical connections, and coolant manifold piping. The distribution of materials in the blanket and shield also vary poloidally. 


\section{Two Dimensional Modeling and Analysis}

Reactor components that are symmetric about a single axis can be effectively studied using twodimensional transport methods. Simplified and complex 2-D modcls in RZ, $X Y$ and $R \Theta$ geometries have been used to determine

- radiation environments and nuclear responses in reactor in-vessel components,

- nuclear responses in the divertor,

- radiation effects in poloidal field coils from streaming through vertical and equatorial ports, - streaming through ICRF, ECRF, NBI, divertor and diagnostic ports to assess the effects of design peculiarities (assembly gaps and penetrations) on the nuclear heating and radiation effects in the $\mathrm{TF}$ coils, and

- biological shielding and building construction to quantify dose rates to operating and casual personnel and estimate skyshine during operation and component replacement.

A two-dimensional $\mathrm{RZ}$ model of a typical neutral beam injector penetration through the blanket and shield is shown in Fig. 5. Included in the model are the plasma region, outboard blanket and shield, a neutral beam injection (NBI) port with a $\mathrm{SS} / \mathrm{H}_{2} \mathrm{O}$-layered beam guard, mid-plane port walls, an adjacent toroidal field coil (modeled approximately), cryostat and biological shield.

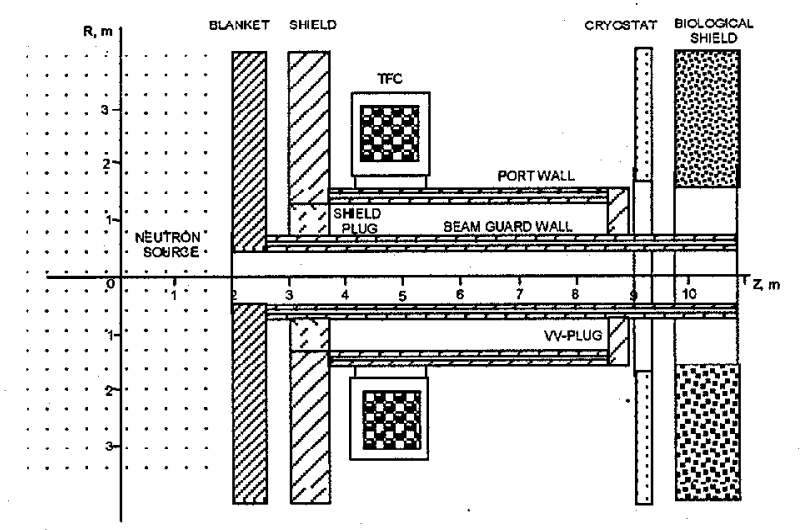

Fig. 5. RZ Model of a Neutral Beam Injection Duct

This model was used to carry out sensitivity calculations of the specific and integral responses in the TF coil as a function of the port radius and wall thickness. Fig. 6 shows, as an example, that an acceptable value for the TF coil nuclear heating of $\sim 0.15$ $\mathrm{kW}$ can be realized only for a port having an equivalent radius of $\sim 0.5 \mathrm{~m}$ and a port wall thickness not less than $\sim 50 \mathrm{~cm}$.

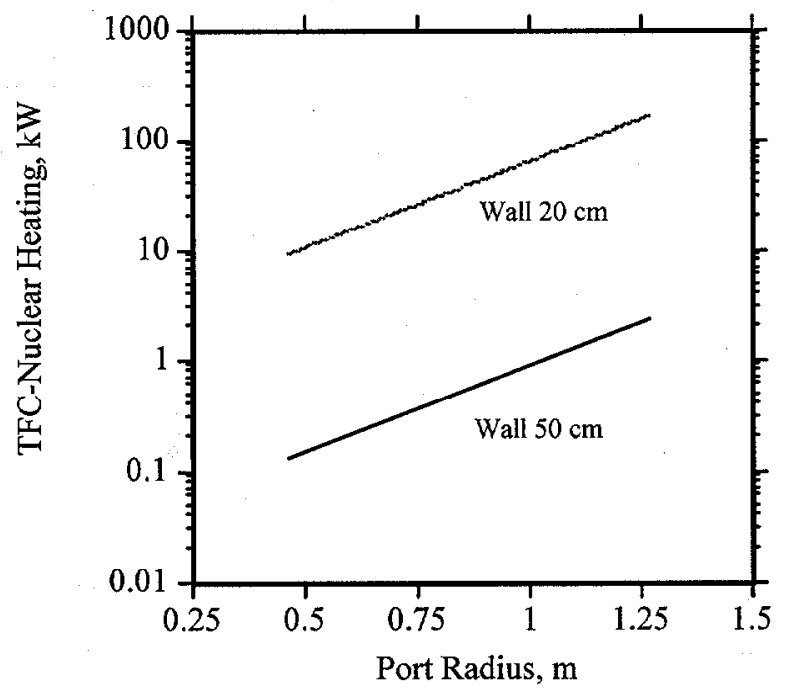

Fig. 6 Nuclear Heating in a TF Coil Near an Open NBI Port as a Function of Port Radius

These data can be used to construct parametric functions relating the nuclear responses in the coils to radiation streaming through a neutral beam injection duct having an equivalent radius of $R_{p}$ and a wall thickness of $T_{w}$. That is

where

$$
R_{n}=N^{*} \exp \left(K_{R} R_{p}-K_{T} T_{w}\right)
$$

$R_{n}$ is the response to be determined, $N$ is a normalization factor, $K_{R}$ is an exponential factor for the port inner radius $R_{p}$, and $K_{T}$ is an exponential factor for the wall thickness $T_{w}$. The expression is valid for values $50<\mathrm{R}_{\mathrm{p}}<130 \mathrm{~cm}$ and $20<\mathrm{T}_{\mathrm{w}}<50 \mathrm{~cm}$.

Normalization and attenuation factors calculated for ITER operating at $1.5 \mathrm{GW}$ fusion power and $1 \mathrm{MW} \mathrm{m}^{-2}$ neutron loading on the first wall are given in Table 2 . The minimum port wall thickness to achieve the response design limits in a TF coil adjacent to the NBI port is summarized in Table 3. For example, the total nuclear energy release in a TFC can be estimated with an accuracy of $\sim 20 \%$ using the expression

$$
\text { TFC-Heating }[k W]=31 \exp \left(0.036 R_{p}-0.14 T_{w}\right) \text {. }
$$

Local and total nuclear responses in the TF coil are proportional to the fast neutron flux incident on the TF coil surfaces. The fast neutron flux is also proportional to the secondary photon source intensity and the nuclear energy release in materials in the space between the shield and the cryostat. 
Table 2. Factors for Estimating Nuclear Responses in a TF Coil Near a NBI Port

\begin{tabular}{|lllll|}
\hline \multicolumn{1}{|c}{ Response } & \multicolumn{1}{c}{ Dimensions } & $\mathrm{N}$ & $\mathrm{K}$ \\
\hline Fast Neutron Flux in the Superconductor & $\mathrm{n} / \mathrm{cm}^{2} \mathrm{~s}$ & $8 \times 10^{10}$ & $\mathrm{~K}_{\mathrm{T}}, \mathrm{cm}^{-1}$ \\
Fast Neutron Fluence in the Superconductor & $\mathrm{n} / \mathrm{cm}^{2} / 1 \mathrm{MWa}$ & $2.5 \times 10^{18}$ & 0.040 & 0.15 \\
Specific Energy release in the Steel TFC-Case & $\mathrm{W} / \mathrm{cm}^{3}$ & 0.023 & 0.038 & 0.15 \\
Specific Energy release in the Nb3Sn & $\mathrm{W} / \mathrm{cm}^{3}$ & 0.0013 & 0.038 & 0.13 \\
Damage in the Cu-stabilizer & $\mathrm{dpa} / 1 \mathrm{MWa}$ & 0.00092 & 0.040 & 0.15 \\
Epoxy-Dose & $\mathrm{rad} / 1 \mathrm{MWa}$ & $1.5 \times 10^{9}$ & 0.040 & 0.15 \\
Total Energy Release in a TFC & $\mathrm{kW}$ & 31 & 0.036 & 0.14 \\
\hline
\end{tabular}

Table 3 Minimum Sidewall Thickness to Achieve Response Design Limits for a NBI Port

\begin{tabular}{|c|c|c|}
\hline Parameter & Limit & Wall Thickness, $\mathrm{cm}$ \\
\hline Fast neutron fluence in $\mathrm{Nb}_{3} \mathrm{Sn}$-superconductor & $\sim 10^{19} \mathrm{n} / \mathrm{cm}^{2}$ & 25 \\
\hline Fast neutron flux & $\sim 10^{11} \mathrm{n} / \mathrm{cm}^{2} \mathrm{~s}$ & 32 \\
\hline Specific energy release in $\mathrm{Nb}_{3} \mathrm{Sn}$-superconductor & $<1 \mathrm{~mW} / \mathrm{cm}^{3}$ & 34 \\
\hline Damage in Cu-stabilizer & $<5 \times 10^{-4} \mathrm{dpa}$ & 35 \\
\hline Integral dose in the Epoxy-insulation & $\sim 10^{9} \mathrm{rad}$ & 36 \\
\hline Specific energy release in the steel TFC-case & $<2 \mathrm{~mW} / \mathrm{cm}^{3}$ & 53 \\
\hline Nuclear heating rate in the TF Coil near the port & $\sim 0.3 \mathrm{~kW}$ & 63 \\
\hline
\end{tabular}

\section{Three-Dimensional Modeling and Analyses}

The performance of the bulk shielding in a fusion reactor can bc rcasonably wcll cstimated using one- and twodimensional radiation transport methods and models. The principal problems facing nuclear analysts and reactor designers is the impact on component performance from radiation streaming through the numerous gaps, slots, and major penetrations that exist in the reactor. In ITER, for example, there are sixty major large penetrations in the blanket and shield that, unless properly shielded, will significantly diminish reactor performance. The ITER ports are summarized in Table 4 . The principal sources of nuclear heating in the $\mathrm{TF}$ coils and cryogenic temperature components inside the cryostat are due to plasma neutrons and prompt secondary gamma rays produced by neutron reactions. A large fraction of the energy from these radiation modes is deposited in the toroidal field coils and inter-coil structure that covers most of the outer surface of the torus.

Table 4. ITER Port Configuration

\begin{tabular}{|c|c|}
\hline & No. of Ports \\
\hline Vertical Ports & \\
\hline Coolant & 10 \\
\hline Diagnostic & 10 \\
\hline \multicolumn{2}{|l|}{ Equatorial Ports } \\
\hline Neutral Beam Injection & 3 \\
\hline Electron Cyclotron Heating & 2 \\
\hline Ion Cyclotron Heating & 3 \\
\hline Remote Handling & 4 \\
\hline Test Blanket & 4 \\
\hline Diagnostic & 4 \\
\hline \multicolumn{2}{|l|}{ Divertor Ports } \\
\hline Remote Handling & 4 \\
\hline Pumping & 16 \\
\hline
\end{tabular}

Three-dimensional Monte Carlo calculations provide the most accurate estimates of radiation streaming through these ports. Modeling the ports is, to some extent, labor intensive and computation time may be long but current computers have high processing speeds that make the effort both worthwhile and effective. A few examples of port analyses are given here to illustrate calculational methods and shield requirements to adequately protect the magnets.

In ITER, the shielding in and around all ports were to satisfy two criteria:

- minimize the nuclear heating in the TF and PF coils and cryo-temperature components near the port and

- reduce the shutdown dose rates at specific points in the cryostat to levels that would permit personnel access operations at two weeks after shutdown.

The requirements to accomplish both place an extreme burden on port shield design.

\section{VI.1. Vertical Port Shield Plug Efficiency}

Three-dimensional Monte Carlo calculations were carried out to determine the shielding as a function of shield plug structure in the vertical port to minimize the nuclear heating rates and other nuclear responses in the TF and PF coils in the vicinity of these ports. The calculational geometry is shown in Fig. 7.

A port shield plug assembly having the equivalent thickness and composition of the primary shield was positioned at three different positions in the vertical port: 
(1) originating at the mouth of the port opening, (2) in the middle of the vacuum vessel and extending up through the port, and (3) with the primary shield in place but no shield extending into the port.

It was shown that neutron and photon streaming through the vertical port has a greater impact on the toroidal coil nuclear heating than streaming through an equatorial port. The vertical port is closer to the TF coils and PF \#2 and \#3. With no shielding plugs in the port, the total nuclear heating ( 20 coils in ITER), particularly in parts of the coils close to the vertical port openings, is $\sim 50 \mathrm{~kW}$; well above the allowed limit of $17 \mathrm{~kW}$. A shielding plug properly situated in the port and similar in composition ( $60 \% \mathrm{SS}-40 \%$ Water) to the primary reactor shield reduces the nuclear heating in the TF coils to an acceptable level of 1-2 kW. The heating rates in the nearby PF coils \#2 and \#3, because of their proximity to the mouth of the port, are strongly dependent on the vertical disposition of the shield plug in the port. See Table 5 .

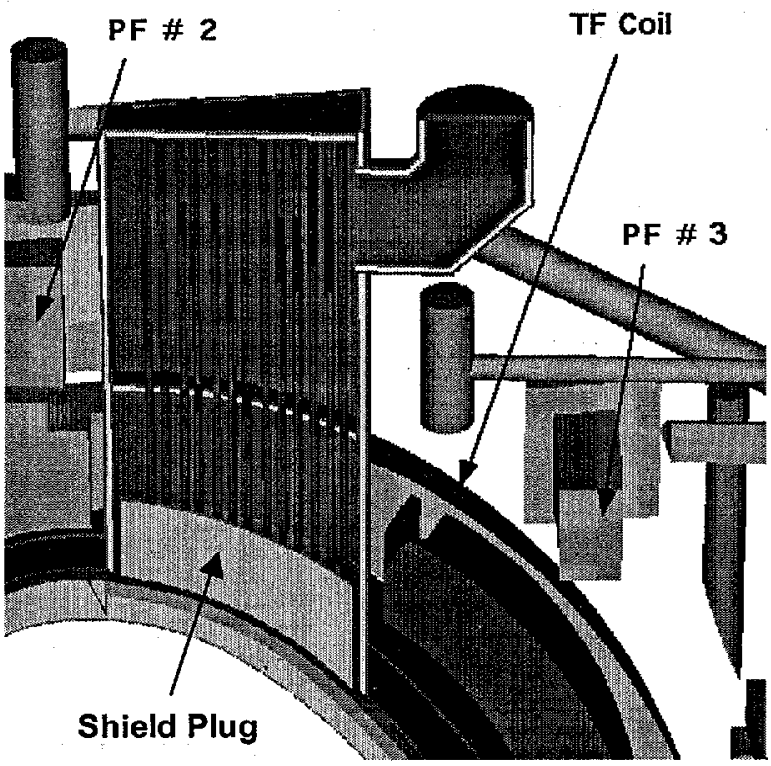

Fig. 7.Vertical Port Model and Adjacent Components

Table 5. Heating Rates in PF Coils $2 \& 3$ vs. Vertical Plug Configuration

\begin{tabular}{|lcc|}
\hline \multicolumn{1}{|c}{ Configuration } & $\underline{\mathrm{PF}-2}$ & $\underline{\mathrm{PF}-3}$ \\
No Shielding Plug & $2.4 \mathrm{~kW}$ & $8 \mathrm{~kW}$ \\
Vertical Plug in Position (1) & $60 \mathrm{~W}$ & $1.7 \mathrm{~kW}$ \\
Vertical Plug in Position (2) & $9 \mathrm{~W}$ & $280 \mathrm{~W}$ \\
Vertical Plug in Position (3) & $4 \mathrm{~W}$ & $40 \mathrm{~W}$ \\
Vertical Plug in Position (3): with & $10 \mathrm{~W}$ & $50 \mathrm{~W}$ \\
coolant pipes in port & & \\
\hline
\end{tabular}

\section{VI.2. Neutral Beam Injection (NBI) Ports}

The NBI Ports are the largest potential source of radiation streaming among the equatorial ports and require careful shielding design. Plasma heating in ITER is accomplished with three neutral beams that enter the plasma region tangent to the plasma axis at $\mathrm{R}=6.5 \mathrm{~m}$ $\left(\sim 35^{\circ}\right.$ to the major radius). The interior spaces of the NBI ports are completely open to allow injection of deuterons from the source directly into the plasma. Neutrons from the plasma stream directly through the ducts and deposit energy in the TF and PF coils, components near the duct wall, and systems inside the cryostat. The angle at which the injection duct enters that plasma brings it in close proximity to the $\mathrm{TF}$ coils limiting the thickness of shielding that can be added to the port walls. Other equatorial ports, for example electron cyclotron (ECH), ion cyclotron (ICH), diagnostic, and test blanket assemblies, are largely filled with the components of these systems that reduce streaming.

According to Table 3 , the minimum NBI duct sidewall thickness to achieve a nuclear heating rate of $\sim 0.3 \mathrm{~kW}$ in a TF coil is $63 \mathrm{~cm}$. Nuclcar hcating in TF coils around the three NBI ports was calculated using Monte Carlo methods with the model shown in Fig. 8. After careful analysis it was determined that a $\sim 60-\mathrm{cm}$ thick shield comprised of $60 \% \mathrm{SS}-40 \%$ water extending from the plasma region to the cryostat was necessary to reduce the heating rate in the magnet to an acceptable value. The results are given in Table 6 .

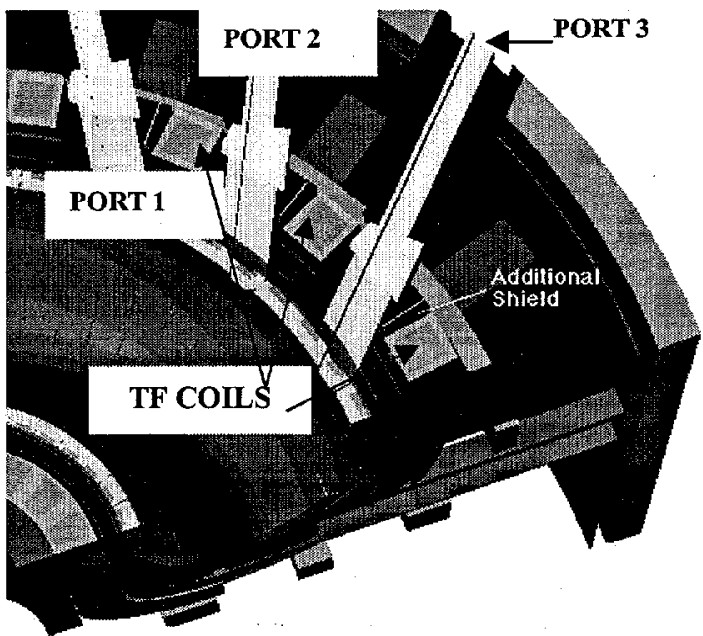

Fig. 8. Calculational Model for Estimating Streaming through the NBI Ducts

Table 6. Nuclear Heating in the TF Coils around the NBI

\begin{tabular}{|c|c|}
\hline \multicolumn{2}{|l|}{ Ports } \\
\hline $\begin{array}{c}\text { TF Coil Location } \\
\text { Intercoil Structure Location }\end{array}$ & $\begin{array}{c}\text { Nuclear } \\
\text { Heating Rate } \\
\text { (W) }\end{array}$ \\
\hline TF coil between $\# 2$ - \#3 NBI Ports & 46 \\
\hline Intercoil Structure Above and Below Port \#2 & 0.6 \\
\hline Total (for 3 NBI Ports) & 140 \\
\hline
\end{tabular}

Nuclear heating rate distribution on the duct wall surface is also important for the mechanical design of the 
duct since much higher heat loads occur at locations near the plasma than at the vacuum vessel surface. The heat load is given by the source neutrons (volumetric heat load) and by X-rays from the plasma (surface heat load). Monte Carlo calculations were conducted using the $90^{\circ}$ model to evaluate these quantities.

The nuclear heat deposition in the inner surface layers of the NBI-ports was also calculated using Monte Carlo methods. Two cases were studied to estimate the nuclear heating in the first $1-\mathrm{cm}$ of the duct wall. In Case 1 the first 1-cm-thick layer is comprised of $\mathrm{Be}, \mathrm{Cu}-\mathrm{H}_{2} \mathrm{O}$ $\mathrm{SS}$ and $\mathrm{SS}-\mathrm{H}_{2} \mathrm{O}$ while in Case 2, the first 1-cm-thick layer is pure stainless steel. The calculated nuclear heating profiles on the NBI port duct wall are shown in Figure 9 (for Case 1) The figure shows the surface nuclear heating distributions (averaged over 1-cm-depth) in the "facing" and "hidden" surfaces of the NBI duct. The "facing" surface is that seen directly by neutrons streaming through the port and the "hidden" surface is that in the shadow of the duct opening. Results are similar for the all SS liner (Case 2).

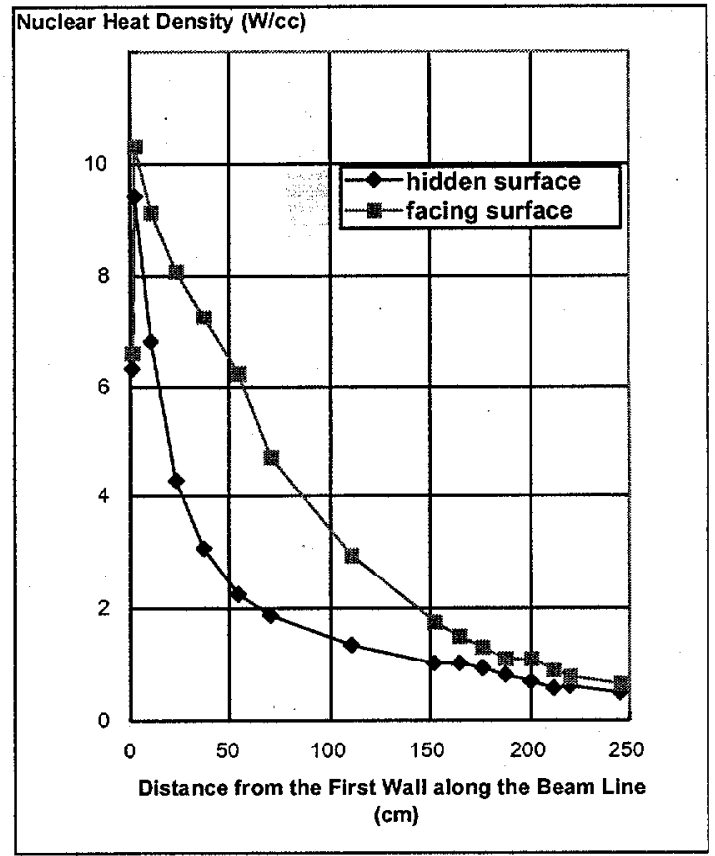

Fig. 9. Nuclear Heating Load on the NBI Port Wall (Averaged over 1-cm Depth in the $\mathrm{Be}, \mathrm{Cu}-\mathrm{H}_{2} \mathrm{O}$ - SS and SS$\mathrm{H}_{2} \mathrm{O}$ Layers)

\section{VI.3. Divertor Pumping Ports}

The divertor ports are comprised of sixteen pumping and four remote handling ports. The pumping ports have cryopumps in the duct space. The remote handling port has a wider port cross section for removal of the divertor cassettes for maintenance and replacement.

This section summarizes the results of 3-D Monte Carlo calculations to estimate the nuclear heating in the
TF and PF coils and associated cryogenic components from streaming through the divertor ports. Fig. 10 shows the calculational model of the divertor pumping port. All of the cryogenic components are modeled; i.e., TF and PF coils, intercoil structure, PF coil clamps, Break Box, and cryogenic coolant feed lines. Six pipes that supply water coolant to the divertor cassettes pass through the top part of the port and through the cryostat. The pipes are parallel to the top surface of the port and the upper and side port walls shield the major length of the pipes. The length of the pipes between the closure plate and the cryostat are not shielded.

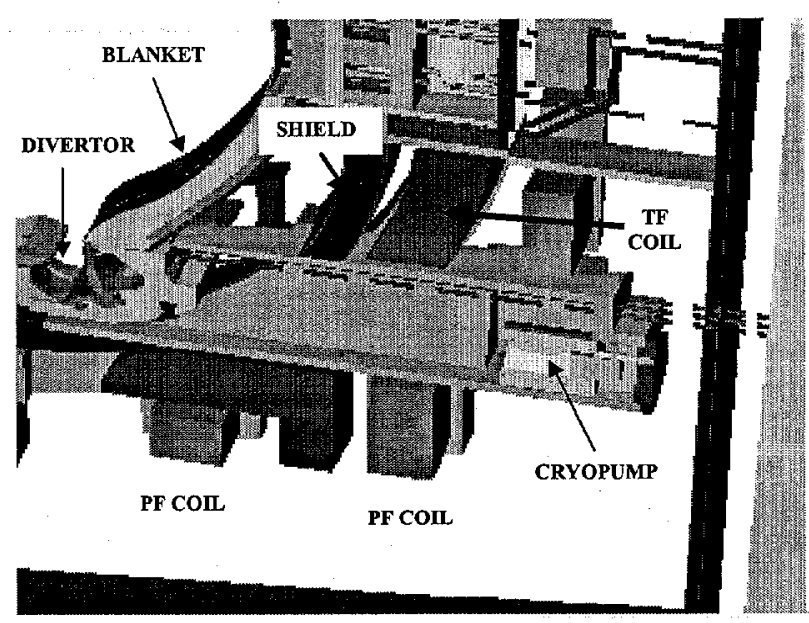

Fig. 10. Divertor Pumping Port Model

The nuclear heating in the TF coil and associated components around the divertor ports is summarized in Table 7 . In this table the nuclear heating rate in the coils around the four remote handling ports has been included.

Table 7. Nuclear Heating Rate in the TF Coil Components around the Divertor Ports

\begin{tabular}{|ccc|}
\hline Location & \multicolumn{2}{c|}{ Nuclear Heating (W) } \\
& For one Port & Total \\
& & (20 Coils) \\
\hline TF Coil & 18 & 350 \\
Central Intercoil Structure & $\sim 3.5$ & 70 \\
Lower Intercoil Structure & $\sim 16$ & 330 \\
\hline Total & $\sim 38$ & 750 \\
\hline
\end{tabular}

A few examples of the detailed calculational effort required to assess and design component shielding minimize the nuclear heating in the superconducting coils have been briefly illustrated. A more complete discussion of port shielding analysis may be found in the ITER Final Design Report documentation. ${ }^{2}$

\section{Other Shielding Issues}

Other. sources of radiation also lead to excess heating the $T F, P F$ and other cryo-temperature components. In ITER, for example, and other fusion 
reactors where water is proposed as the coolant, radioactive ${ }^{16} \mathrm{~N}$ will be produced via $(n, p)$ reactions in ${ }^{16} \mathrm{O}$. Water coolant return lines that pass close to these components will be exposed to 6.13 and $7.12 \mathrm{MeV}$ photons that arise from ${ }^{16} \mathrm{~N}$ decay. Detailed analyses are necessary to determine optimum routing of the coolant pipes and local pipe shielding. Typical results obtained from ${ }^{16} \mathrm{~N}$ photon energy deposition in the ITER TF and PF coils are summarized in Tables 8 and 9, respectively.

Table $8 .{ }^{16} \mathrm{~N}$ Decay Gamma-Ray Nuclear Heating in the Toroidal Field Coils

\begin{tabular}{|lc|}
\hline \multicolumn{1}{|c|}{ Port } & $\mathrm{kW}$ \\
\hline Vertical Ports & 0.34 \\
Equatorial Ports & 1.21 \\
Divertor Ports & $<0.1$ \\
\hline
\end{tabular}

Table 9. ${ }^{16} \mathrm{~N}$ Decay Gamma-Ray Nuclear Heating in the Poloidal Field Coils

\begin{tabular}{|l|l|}
\hline \multicolumn{1}{|c|}{ Port } & $\mathrm{kW}$ \\
\hline \hline Vertical Ports & 0.12 \\
Equatorial Ports & 1.00 \\
Divertor Ports & 0.08 \\
\hline
\end{tabular}

The energy deposition in the ITER TF coils from all sources is summarized in Table 10 . The total heating rate in the coils is $-7.3 \mathrm{~kW}$ giving a safety factor of approximately two compared to the design limit of 17 $\mathrm{kW}$.

Table 10. Integrated Nuclear Heating in the Toroidal Field Coils and Intercoil Structures

\begin{tabular}{|lc|}
\hline \multicolumn{1}{|l|}{ TF Coil Components and Locations } & $\mathrm{kW}$ \\
\hline Inboard Legs & $\sim 1.2$ \\
\hline Upper Ports (20): & \\
\hline Blanket cooling pipe ports (10) & $\sim 1.3$ \\
Diagnostic ports (10) & $\sim 0.2$ \\
Intercoil structures (20) & $\sim 0.3$ \\
Mid-Plane Ports (20): & $<0.3$ \\
\hline ICRF Ports (3) & 0.14 \\
NBI Ports (3) & $<0.2$ \\
ECH Ports (2) & $<0.1$ \\
R. H. Ports (4) & $\sim 0.05$ \\
Test Blanket Ports (4) & $\sim 0.07$ \\
Diagnostic Ports (4) & \\
Divertor Ports (20): & $\sim 0.4$ \\
\hline Toroidal Field coils & $\sim 0.4$ \\
Intercoil structures & \\
N16 Decay Gamma Rays: ${ }^{*}$ & 0.34 \\
\hline Vertical Ports & 1.21 \\
Equatorial Ports & $<0.1$ \\
Divertor Ports & $\sim 7.3$ \\
\hline
\end{tabular}

\section{Conciusion and Comments}

This paper has focused on the shielding required to minimize the nuclear heating in the TF and PF coils of a fusion reactor. As noted above, this is first requirement facing nuclear and design engineers. Unless the coils are properly protected from the plasma radiation by both the blanket-shield bulk shielding and the proper major penetration shielding, the coils could be rendered ineffective or require so much additional refrigeration that the cost would be overwhelming.

The merits of tailoring shielding material composition have only been mentioned briefly. Reducing the fractions of certain elements in the structural materials, particularly if it is stainless-steel, can considerably reduce activation and, in so doing, reduce the dose rate after shutdown thus making human access more feasible.

When the protcction and performance of the invessel components have been assured, then attention can be directed to ex-vessel shielding. The reactor containment building construction will, to a large extent, determine the disposition of biological shielding. If the reactor is in ground as in the case of ITER, the shielding will serve largely for the protection of equipment in galleries outside the containment vessel. The shielding along the top of the containment will have to be sufficient to assure the safety of opcrating personncl.

1 The author gratefully acknowledges the work of the ITER Joint Central Team nuclear analysts and design staff that is reflected in this paper.

${ }^{2}$ R. T. Santoro, V. Khripunov, and H. Iida, "ITER Nuclear Analysis Report", G 73 DDD 1 98-06-17 WO.2, ITER Garching Joint Work Site, Garching, Germany 